\title{
Preliminary report of a new method of surgical treatment of haemorrhoids
}

\author{
Muhammad Assem Kubtan* \\ Department of surgery, Faculty of medicine, Syrian Private University, Damascus, Syria
}

\begin{abstract}
When conservative treatment fails, many invasive techniques developed to treat hemorrhoids. This study aims to compare the results of method designed by the author. (Disconnection of Systemic from Visceral Circulation at the anal canal DSVC) with the classical surgery known as Milligan \& Morgan approach M\&M. We conducted controlled, non-blinded, randomized study, involved 72 patients, took place under the supervision of one surgeon (the author) in Damascus hospital in Syria. For DVSC the mean procedures time $(10+/-0)$ minutes (ranged between 8-21 minutes) and duration of hospitalization $4 \pm 2$ hours post operatively.

The mean procedures time for M\&M $(20 \pm 0)$ minutes (ranged between 18-35 minutes) and hospitalized for two day post-operatively. We recommend DSVC method for $2^{\text {nd }}, 3^{\text {rd }}$ degree and prolapsing hemorrhoids, it is easy to perform, not associated with serious complications and has a good and satisfactory results. Compared to other surgical procedures, less painful, blood stained anal discharge but no actual bleeding, and does not require specific device (Doppler sounder), or Stapler, and satisfy the patient.
\end{abstract}

\section{Introduction}

\section{Epidemiology}

More than 10 million of the population complain of hemorrhoids in United States Figure 1, more than a million and half are trying to benefit from different therapeutic modalities, although it has been stated that $50 \%$ of the population will experience symptomatic hemorrhoid disease at some point in their lives.

Hemorrhoids affect all age groups, peak incidence of symptomatic disease 45-65 years 2 , there is a slightly increased prevalence in women. Hemorrhoids, exists in healthy people, it become symptomatic when enlarge, inflamed, bleed, develop prolapses or thrombosis.

An evidence support that hemorrhoidal bleeding is arterial nature, supported by $\mathrm{PO} 2$ calibration.

\section{Anatomical principle}

Anal canal 1, is approximately $4 \mathrm{~cm}$ in, close to levator - sphincteric complex. Anus is lined by anoderm, richly innervated with somatic sensory nerves, and supplied by the inferior hemorrhoidal vessels. The dentate line is the point at which the squamous anoderm meets the columnar mucosa it lies about $3 \mathrm{~cm}$ above the anal verge. The dentate line is the major anatomic reference point when considering surgical treatment. Internal hemorrhoids are cushions of fibrovascular tissue proximal to the dentate line, with the external hemorrhoid distal to it [1-5].

The anal canal forms [1,3] a discontinuous layer of thickened tissue, creating "cushions" found in the left lateral, right lateral anterior, and right lateral posterior positions, there are frequent anatomic variations of this arrangement These cushions receive their blood supply primarily from the superior hemorrhoidal artery and branches of the middle and the inferior hemorrhoidal arteries. The venous drainage is provided by the superior, middle, and inferior hemorrhoidal veins, representing a communications between the portal and systemic circulations, and forming direct arteriovenous communications within the cushions, and for these reasons, hemorrhoidal bleeding is arterial in nature.

The submucosal layer of these cushions contains the vessels mentioned and also rich in muscular fibers, which arise from both the internal sphincter and the conjoined longitudinal muscle. These muscular fibers (the muscularis submucosa) help to maintain

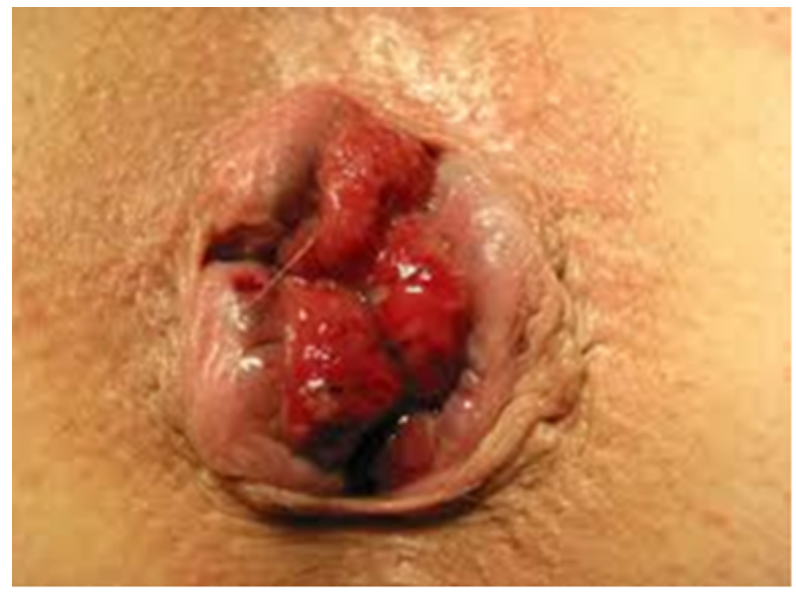

Figure 1. Second degree Heamorroids

Correspondence to: Muhammad Assem Kubtan Department of surgery, Faculty of medicine, Syrian Private University, Damascus, Syria, Tel: 00963944271215; E-mail:makubtan@gmail.com

Key words: hemorrhoids, hemorrhoids cushions, dentate line

Received: September 05, 2015; Accepted: October 03, 2015; Published: October 07, 2015 
adherence of these tissues to the underlying internal sphincter. With time and aging, starting as early as the second or third decade of life associated with other factors such as heredity, chronic constipation, lack of fibers diet etc, this supporting tissue can deteriorate or weaken, leading to distal displacement of the cushions and venous distention, erosion, bleeding, thrombosis and hemorrhoids prolapse.

The hemorrhoids have an important role in the maintenance of anal continence, contributing $15 \%-20 \%$ of resting pressure of the anal verge. They protect the sphincter mechanism during defecation, and providing complete closure of anal opening, while performing a Valsalva maneuver.

Hemorrhoids are formed during the uterine life and continue with their physiological role in a healthy adult subjects.

The aim of this study is to compare results of DVSC for $2^{\text {nd }}, 3^{\text {rd }}$ and prolapsing hemorrhoids with M\&M.

\section{Patients and method}

Between March 2010 to October 2013, after having their consent, 72 patients enrolled in this study. Their ages ranged between 18-70 years, included 37 (24 males 65\%), have been subjected to the method DVSC, compared with 35 (22 males 63\%) treated using the classical procedures M\&M.

DVSC performed by using PROLINE No. 1 stiches with round twin needles, one of the needles is passed about $5-8 \mathrm{~mm}$ aside of the hemorrhoidal cushion from inside the anus above the dentate line through the ano rectal space heading to outside through para anal cutaneous area $2 \mathrm{~cm}$ proximal to anal orifice, the second needle also passed in the same manner through the other side of the hemorrhoidal cushion and about $2.5 \mathrm{~cm}$ apart between the two needles outlets, the two ends ligated tightly together after threading one end of stitches through a $3 \mathrm{~mm}$ diameter of $2.5 \mathrm{~cm}$ length of poly ethylene tube producing principally local avascular necrosis and disconnection between systemic and portal system and dearterialisation of the hemorrhoidal cushion Figure 2. This procedures were repeated to the other two hemorrhoidal cushions Figure 3.

The other group of patients treated surgically using the classical procedures of M\&M.

\section{Results}

For DVSC The mean procedures time $(10 \pm 0)$ minutes (ranged between 8-21 minutes) and duration of stay in the hospital $4 \pm 2$ hours post operatively.

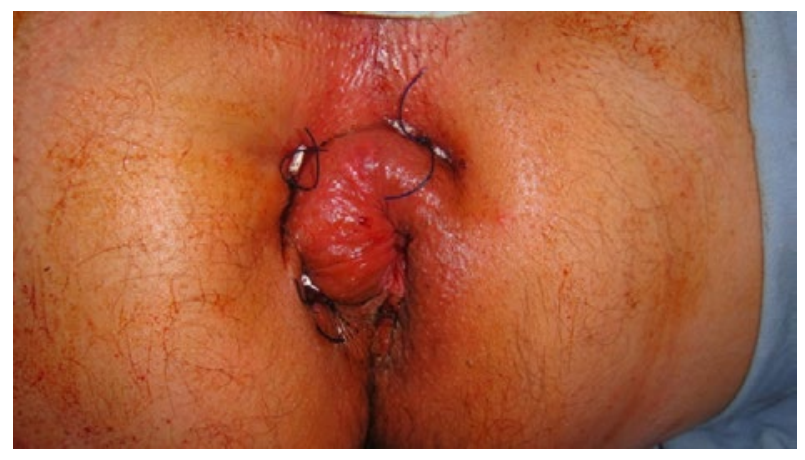

Figure 2. Disconnection of Systemic from Visceral Circulation through the anal canal DSVC.

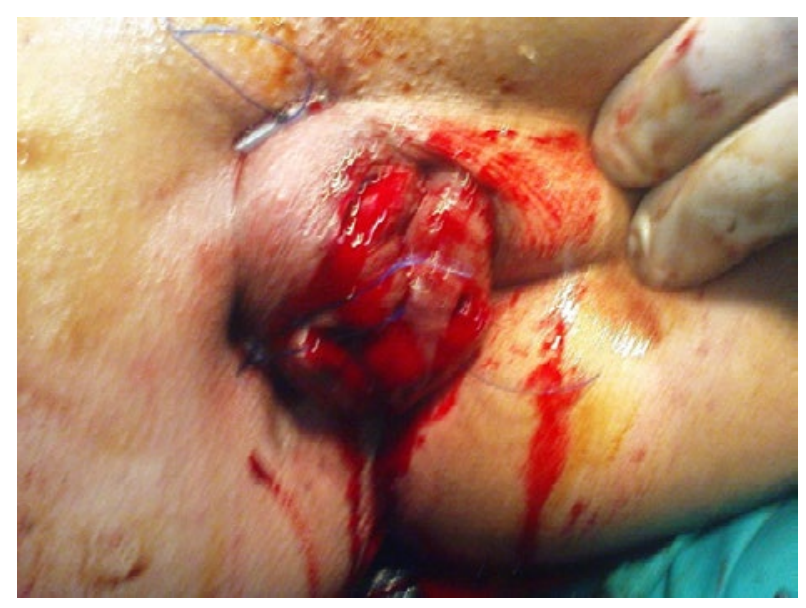

Figure 3. Disconnection of Systemic from Visceral Circulation through the anal canal DSVC.

And the mean procedures time for M\&M $(20 \pm 0)$ minutes (ranged between 18-35 minutes) and the patient was discharged from the hospital two days post-operation.

Both procedures carried out by same surgeon, under caudal anesthesia to all patients, and tracheal intubation were used only in three cases $8.5 \%$ of $\mathrm{M} \& \mathrm{M}$ group.

All patients received three fingers manual dilatation of anus MDA.

For those who underwent M\&M, they suffered 100\% from sever anal pain after the caudal anesthetic effect have faded, in the first 24 hours all received Pethidine $100 \mathrm{mg}$ intramuscular injections primarily followed by Pethidine $100 \mathrm{mg}$ diluted in $20 \mathrm{ml} \mathrm{N}$. Saline and given Iv intermittently in divided doses not exceeding $2 \mathrm{ml}$ per hour, followed by Diclofenac $75 \mathrm{mg}$ injections PRN till discharge. One male (2.8\%) developed retention of urine while in hospital and catheterized for three days, one patient $(2.8 \%)$ developed anal stricture after being discharged from hospital in two weeks requiring readmission for anal dilatation.

All Patients 100\% underwent DVSC received single $100 \mathrm{mg}$ Pethidine intramuscular injection post operatively when the effect of caudal anesthetic has faded, and discharged from hospital $4 \pm 2$ hours and were asked to report to the out patients department OPD three days post operatively Figure 4 for review and removal of the perianal DVSC stitches.

Both groups instructed to attend OPD after 2 weeks, 4 weeks, and 6 months.

Both groups advised to take high fiber diet from the first day post operatively, also advised to have a lukewarm salted sits bath three times a day for two weeks.

They were all given a prescription of Potassium Diclofenac $50 \mathrm{mg}$ orally twice to three times a day with Domperidone $10 \mathrm{mg}$ tablet twice daily.

Those how suffered from persistent pain in ano were advised to have more lukewarm salted sits bath and Diclofenac $75 \mathrm{mg}$ injection IM, PRN not exceeding two injections a day.

It was noticed that patients, who underwent DVSC procedures experienced immediate relief of anal pain Figure 5 following removal of stitches. Two weeks later they were seen in the OPD and there were 


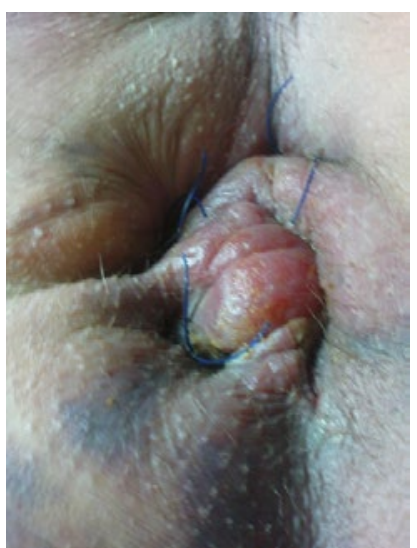

Figure 4. $3^{\text {rd }}$ day post operatively before removing prolene sutures.

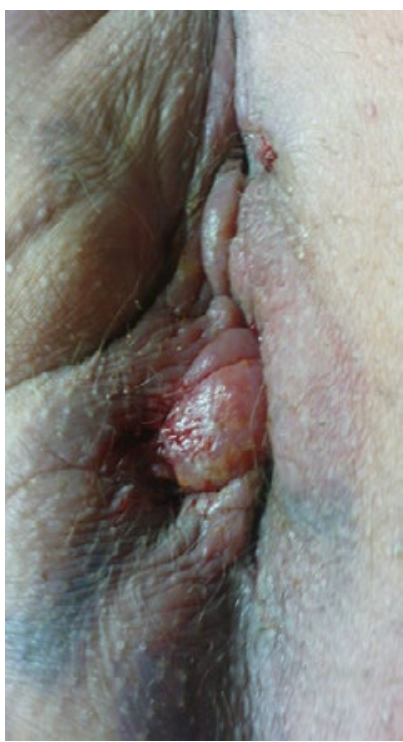

Figure 5. $3^{\text {rd }}$ day post operatively after removing prolene sutures.

considerable regression in the pain and edema Figure 6, and four weeks later they were seen in OPD and were almost completely pain free without any discomfort in defecation or sitting, and the cushions size have regressed almost completely with normal anal appearance Figure 7 and without bleeding or other serious symptoms.

The only complication we encountered was cutaneous ulceration deep to polyethylene tubes seen in 4 patients $10.8 \%$ lasted less than a week and healed completely.

For those who underwent M\&M surgery, 18 had residual complaint $51 \%$ of pain and discomfort on defecation 2 weeks post operatively and two of them $5.7 \%$ were readmitted for manual dilatation of the anus, 3 suffered $8.5 \%$ from persistent anal bleeding, when reviewed 4 weeks later in OPD 5 patients 14\% complained of moderate pain and discomfort on defecation and 3 had $8,5 \%$ intermittent blood stained anal discharge.

We fail to see any of both groups six month later in OPD despite attempting to contact patients by phone, none of the DSVC group had complaint, while 4 of those $11.4 \%$ underwent M\&M still c/o discomfort on deification.

\section{Discussion}

Several options for treating hemorrhoids, including conservative management, by increasing fiber intake to combat chronic constipation, encouraging the movement, avoiding prolonged sitting, and in elderly encouraging the actions of regular fecal evacuation by other means. Hemorrhoids is considered as a set of arterial-venous vascular complex residing between the mucous layer the lamina muscularis mucosa muscle and anal sphincter muscular structure (corpus cavernosum recti).

Haemorrhoidal cushions share in physiology of anal sphincter mechanism, but when it became engorged and enlarged it evolves into clinical condition that requires treatment. Our method described is effective and eliminates the need for surgical excision.

In our society we deal with people of moderate income who have limited access to government services due to lengthy waiting list and current unrest, and the majorities have no insurances facilities.

DVSC procedures represent an easy way of treating hemorrhoids leading to immediate arrest of bleeding, regression in size of prolapsed

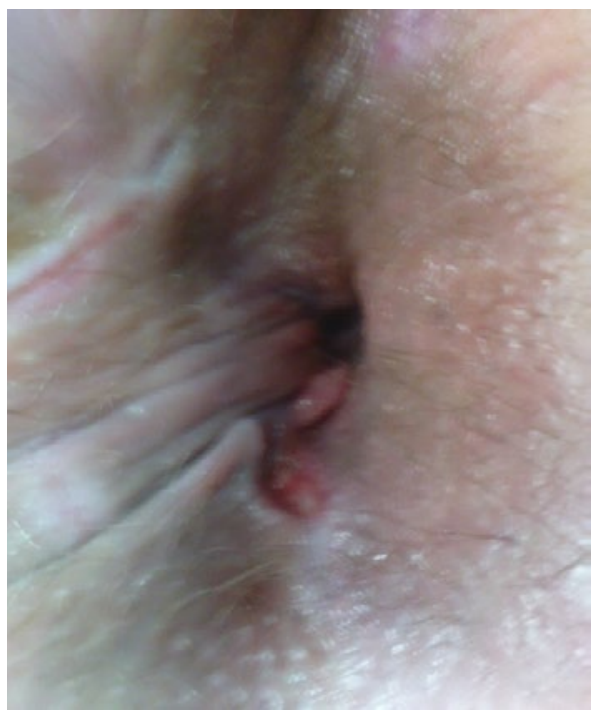

Figure 6. Two weeks after surgery.

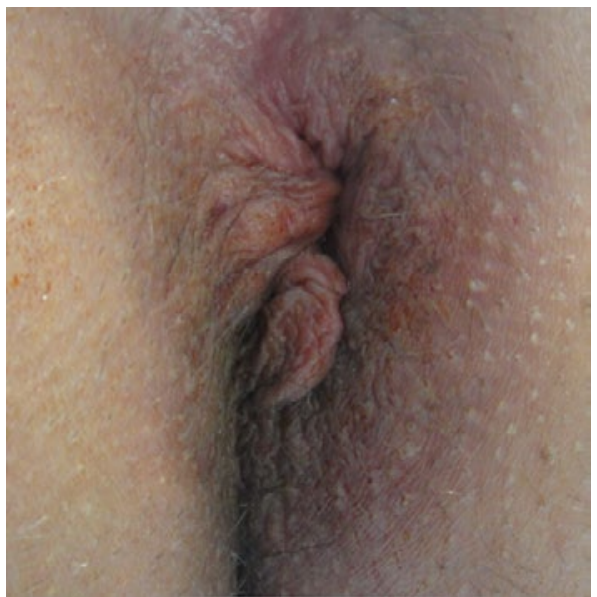

Figure 7. One month after surgery. 
hemorrhoidal cushions, it is a day case surgery, less complicated, easy to perform, and does not require a special needs such as Doppler sounder or expensive stapler instruments [6-20].

We recommend the adoption of the DVSC method, as an easy way not associated with any serious complications, it has a good and satisfactory results. Compared to other surgical procedures, easy to perform, less painful, blood stained anal discharge but no actual bleeding, and achieve satisfaction of the patient and early return to work.

We believe that disconnecting the systemic from the visceral circulation process is easy to learn and less invasive than the other surgical procedures, least in the incidence of recurrence, and we have not encounter any relapse three years post operatively, it is least painful surgical procedures and pain is encountered commonly during the first three days post operatively .

Pitfalls: We were concerned about the possibility of developing high fistula in an, and we can state confidently that this worries has no basis in patients subjected to the DVSC procedures.

\section{Conclusion}

We recommend DVSC Disconnecting the systemic from visceral circulation it is without complications of value in treatment of hemorrhoids of second and third degree and prolapsed hemorrhoids, it is less painful, satisfactory, the cost is $40 \%$ less than other surgical modalities.

Our view that this technique should be considered and require further study in other centers, to repeat our results and could be instituted in any societies were short hospitalization and low cost has an important role in choosing the type of surgical treatment instituted.

\section{Acknowledgments}

I would like to extend my appreciation and thanks for the help and support provided by Professor Abdul Razak Cheikh Issa the President of the Syrian Private University, and a special thanks to my colleague Professor Yousser Mohammad for her assistance in editing.

\section{References}

1. Milligan ETC, Morgan CN, Jones LE, Officer R (1937) Surgical anatomy of the ana canal and operativetreatment of hemorrhoids. Lancet 2: 1119-1124.

2. Johanson JF, Sonnenberg A (1990) The prevalence of hemorrhoids and chronic constipation. An epidemiologic study. Gastroenterology 98: 380-386. [Crossref]

3. Bleday R, Pena JP, Rothenberger DA, Goldberg SM, Buls JG (1992) Symptomatic hemorrhoids: current incidence and complications of operative therapy. Dis Colon Rectum 35: 477-481. [Crossref]

4. Loder PB, Kamm MA, Nicholls RJ, Phillips RK (1994) Haemorrhoids: pathology, pathophysiology and aetiology. Br J Surg 81: 946-954. [Crossref]

5. MacRae HM, McLeod RS (1995) Comparison of hemorrhoidal treatment modalities. A meta-analysis. Dis Colon Rectum 38: 687-694. [Crossref]

6. Dennison AR, Paraskevopoulos JA, Kerrigan DD, Shorthouse AJ (1996) New thoughts on the aetiology of haemorrhoids and the development of non-operative methods for their management. Minerva Chir 51: 209-216. [Crossref]

7. Mehigan BJ, Monson JR, Hartley JE (2000) Stapling procedure for haemorrhoids versus Milligan-Morgan haemorrhoidectomy: randomised controlled trial. Lancet 355 : 782-785. [Crossref]

8. Rowsell M, Bello M, Hemingway DM (2000) Circumferentialmucosectomy (stapled haemorrhoidectomy) versus conventional haemorrhoidectomy: randomised controlled trial. Lancet 355: 779-781. [Crossref]

9. Ganio E, Altomare DF, Gabrielli F, Milito G, Canuti S (2001) Prospective randomized multicentre trial comparing stapled with open haemorrhoidectomy. Br J Surg 88: 669674. [Crossref]

10. Shalaby R, Desoky A (2001) Randomized clinical trial of stapled versus MilliganMorgan haemorrhoidectomy. Br J Surg 88: 1049-1053. [Crossref]

11. Ortiz H, Marzo J, Armendariz P (2002) Randomized clinical trial of stapled haemorrhoidopexy versus conventional diathermy haemorrhoidectomy. Br J Surg 89: 1376-1381. [Crossref]

12. Wilson MS, Pope V, Doran HE, Fearn SJ, Brough WA (2002) Objective comparison of stapled anopexy and open hemorrhoidectomy: a randomized, controlled trial. Dis Colon Rectum 45: 1437-1444. [Crossref]

13. Au-Yong I, Rowsell M, Hemingway DM (2004) Randomised controlled clinical trial of stapled haemorrhoidectomyvs conventional haemorrhoidectomy; a three and a half year follow up. Colorectal Dis 6: 37-38. [Crossref]

14. Hasse C, Sitter H, Brune M, Wollenteit I, Lorenz W, et al. (2004) [Haemorrhoidectomy: conventional excision versus resection with the circular stapler. Prospective, randomized study]. Dtsch Med Wochenschr 129: 1611-1617. [Crossref]

15. Ganio E, Altomare DF, Milito G, Gabrielli F, Canuti S (2007) Long-term outcome of a multicentre randomized clinical trial of stapled haemorrhoidopexy versus MilliganMorgan haemorrhoidectomy. Br J Surg 94: 1033-1037. [Crossref]

16. Tjandra JJ, Chan MK (2007) Systematic review on the procedure for prolapse and hemorrhoids (stapled hemorrhoidopexy). Dis Colon Rectum 50: 878-892. [Crossref]

17. Annals of Surgical Innovation and Research

18. Burch J, Epstein D, Baba-Akbari A, Weatherly H, Fox D, et al. (2008) Stapled haemorrhoidectomy (haemorrhoidopexy) for the treatment of haemorrhoids: a systematic review and economic evaluation. Health Technol Assess 12: iii-iv, ix-x, 1-193. [Crossref]

19. Laughlan K, Jayne DG, Jackson D, Rupprecht F, Ribaric G (2009) Stapled haemorrhoidopexy compared to Milligan-Morgan and Ferguson haemorrhoidectomy: a systematic review. Int J Colorectal Dis 24: 335-344. [Crossref]

20. Stapled haemorrhoidopexy for the treatment of haemorrhoids (2011) NICE technology appraisal guidance 128 .

Copyright: (C2015 Kubtan MA. This is an open-access article distributed under the terms of the Creative Commons Attribution License, which permits unrestricted use, distribution, and reproduction in any medium, provided the original author and source are credited. 